\title{
TPPADS: An Expert System Based on Multi-branch Structure for Tianjin Planting Pest Assistant Diagnosis
}

\author{
Zhigang $\mathrm{Wu}^{1}$, Yichuan Bai ${ }^{2}$, Han Huang ${ }^{1}$, Wenxin $\mathrm{Li}^{1}$, Zhimei $\mathrm{Li}^{1}$, and Zhihong $\mathrm{Li}^{1,3, *}$ \\ ${ }^{1}$ China Agricultural University, Beijing, 100193, China \\ ${ }^{2}$ Tianjin Institute of Plant Protection, 30012, China \\ ${ }^{3}$ Department of Entomology, College of Agronomy and Biotechnology, \\ China Agricultural University, Beijing 100193, P. R. China, \\ Tel.: +86-10-62731299; Fax: +86-10-62733404 \\ lizh@cau.edu.cn
}

\begin{abstract}
At present, green plants exist in all aspects of our lives. And statistics shows that the pest species of green plants is very large. Thus accurate and rapid diagnosis is regarded as an essential component of green plant protection. Moreover, we couldn't find relevant information easily. That is why pest diagnosis is difficult and inefficient for technicians and farmers. In view of the above, the expert systems have been widely used in pest identification. However, most of traditional expert systems for assistant diagnosis of green plant pests are based on dichotomous structure. They are not flexible enough and only equal the electronic dichotomous keys. Compared with dichotomous structure, the system based on multi-branch structure has more advantages for accurate and rapid diagnosis. This paper describes the design and development of a web-based green plant pest expert system as part of Tianjin science and technology cooperation project. Based on user needs, Tianjin Planting Pest Assistant Diagnosis System (TPPADS) was developed with ASP.NET, C\# and Microsoft SQL server 2008 database. It can show many features simultaneously. Meanwhile, data maintaining is also very easy and simple as same as the Microsoft Windows Explorer. The system included about more than 300 species of green plant pests. Diagnosis knowledge was obtained from Tianjin Institute of Plant Protection. TPPADS can be used as a diagnosis tool and information database both for plant protection professionals and farmers. We believe its application prospect should be well.
\end{abstract}

Keywords: green plant, expert system, multi-branch structure, pest diagnosis.

\section{Introduction}

At present, green plants exist in all aspects of our lives. And statistics shows that the pest species of green plants is very large. There are about 500 kinds of pests, who can harm green plants in Tianjin, which is one of the supper cities in China. Identification of pests is very difficult for farmers and technicians. Not only pests' information is not enough to

* Corresponding author.

D. Li, Y. Liu, and Y. Chen (Eds.): CCTA 2010, Part III, IFIP AICT 346, pp. 572-579, 2011.

(C) IFIP International Federation for Information Processing 2011 
meet the needs of farmers and technicians, but also the expert resources of green plant pest are very scarce. Usually, human experts are needed to provide the diagnostic knowledge, however, in some areas, pest management experts are not readily available to carry out disease diagnosis or insect identification [1]. Meanwhile, Lack of database or expert system is one of the reasons for this situation. They find information difficulty, such as biological characteristics, control method, pest images, etc.

Expert systems (ES) are a branch of applied artificial intelligence (AI), and were developed by the AI community in the mid-1960s. The basic idea behind ES is simply that expertise, which is the vast body of task-specific knowledge, is transferred from a human to a computer [2]. The essence of an expert system is to mimic expertise and distribute expert knowledge into non-experts' hands. This can be enhanced significantly by using the Internet. ES solutions are based on reasoning by using problem domain knowledge and heuristics. Hence, ES approach is the most suitable methodology for simulating human experts. Most of the ESs for ship design is aimed at development of assistance to deal with the complex characteristics of design problem [3].

Expert systems have been applied in agriculture from 1980s [4-20]. Most of them are developed for crop production and pest management [21-26], animal husbandry and aquaculture[27-30]. At the same time, ESs are also widely used in forestry, medicine, industry etc[31-33]. Some are stand-alone early [34-37], many of them are web-based at present [38-41]. Some ESs also began to integrate mobile communication systems, GIS technology etc [42-44].

This paper discusses our experience in developing and evaluating a web-based expert system for identification of green plant pests, named as TPPADS (Tianjin Planting Pest Assistant Diagnosis System). The system included about more than 300 species of green plant pests. It has been developed by China Agricultural University and Tianjin Institute of Plant Protection. TPPADS could be used as a diagnosis tool and information database both for plant protection technicians and farmers.

\section{Users' Needs and Knowledge Acquisition}

\subsection{Users' Needs}

Efficient identification work is a vital to help to make a decision about the pest control measures. When applying an expert system for technicians and farmers, it is necessary to investigate both their attitudes toward that the system. Essentially, understanding their perceptions toward the tool is a crucial issue for enhancing effect of green plant protection. In order to meet the requirements of Tianjin Institute of Plant Protection work, we had several meetings to discuss the system requirements, and careful analysis. The needs analysis report shows that:

- Need of basic information in a large number of pests. Technicians and farmers couldn't find relevant information easily.

- Need of assistant diagnosis system. Accurate and rapid diagnosis is regarded as an essential component of green plant protection. That is why pest diagnosis is difficult and inefficient for technicians and farmers. 
- Friendly interface and easy operation. One of the most important design considerations behind the system was that a system should be as user friendly as possible. Understanding of the user's cognitive structure and the users' task is a critical component in the development of user-centered interface design. A good interface will enhance user/expert system interaction and task performance [45]. Simple operation allows users to easily use the system.

- Interactive Consulting. Users can get experts' answer about some problems through interactive consulting on-line.

\subsection{Knowledge Acquisition and Information Collection}

Knowledge acquisition (KA) is the process of transferring knowledge from the knowledge source to knowledge engineer (or expert system builder). To acquire the required knowledge, we followed the KA procedure discussed in Morpurgo[46] (Morpurgo et al., 2001) and Wada etc [47].The knowledge, symptom descriptions and the rules from domain experts, i.e. entomologist and psychopathologists.

Pest information (e.g. species' morphological characteristics, biology, geographic distribution, etc.) were acquired from experts interviews and literature such as textbooks, primary and secondary literature, papers, etc. We also collected a large number of pictures by photographing. it's about 300 species of green plant pests in Tianjin.

\section{System Design and Development}

\subsection{Software and Database}

TPPADS was designed to run on the internet. Its development was based on the use of internet techniques and SQL programming languages. It was developed with ASP.NET and C\#. The server database played a very important role in developing TPPADS. It was used to sort all the information and knowledge which was needed to actualize every function of the expert system. In TPPADS, there are 5 databases including a user information database, basic information database and identification knowledge database etc. They were all designed using MS SQL Server 2008 Database.

\subsection{Inference Process}

Amongst the different methods for representing the knowledge [48], production rules are the most frequently used for diagnostic expert systems [14,17]. A rule is composed of a list of IF conditions and a list of THEN and ELSE statements about the appropriate solution to the problem. A disadvantage of a rule-based system is that the knowledge is not organized in a real structure [49]. Most of traditional expert systems for assistant diagnosis of green plant pests are based on dichotomous structure which is rule-based. They are not flexible enough and only equal the electronic dichotomous keys. However, hierarchical structure provides a natural structure for the knowledge and allows the building of expert systems that can be easily modified and adapted. In hierarchical structure, knowledge is organized in a decision tree, with nodes at different 

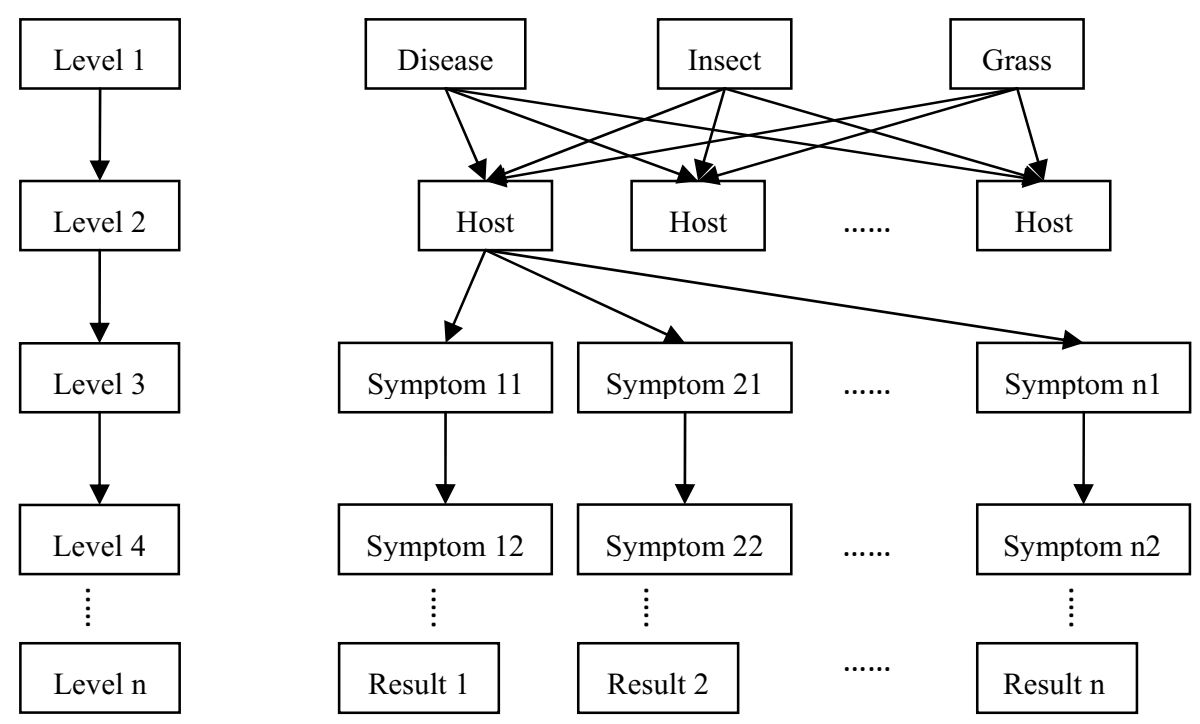

Fig. 1. The Inference diagram of multi-branch structure of TPPADS

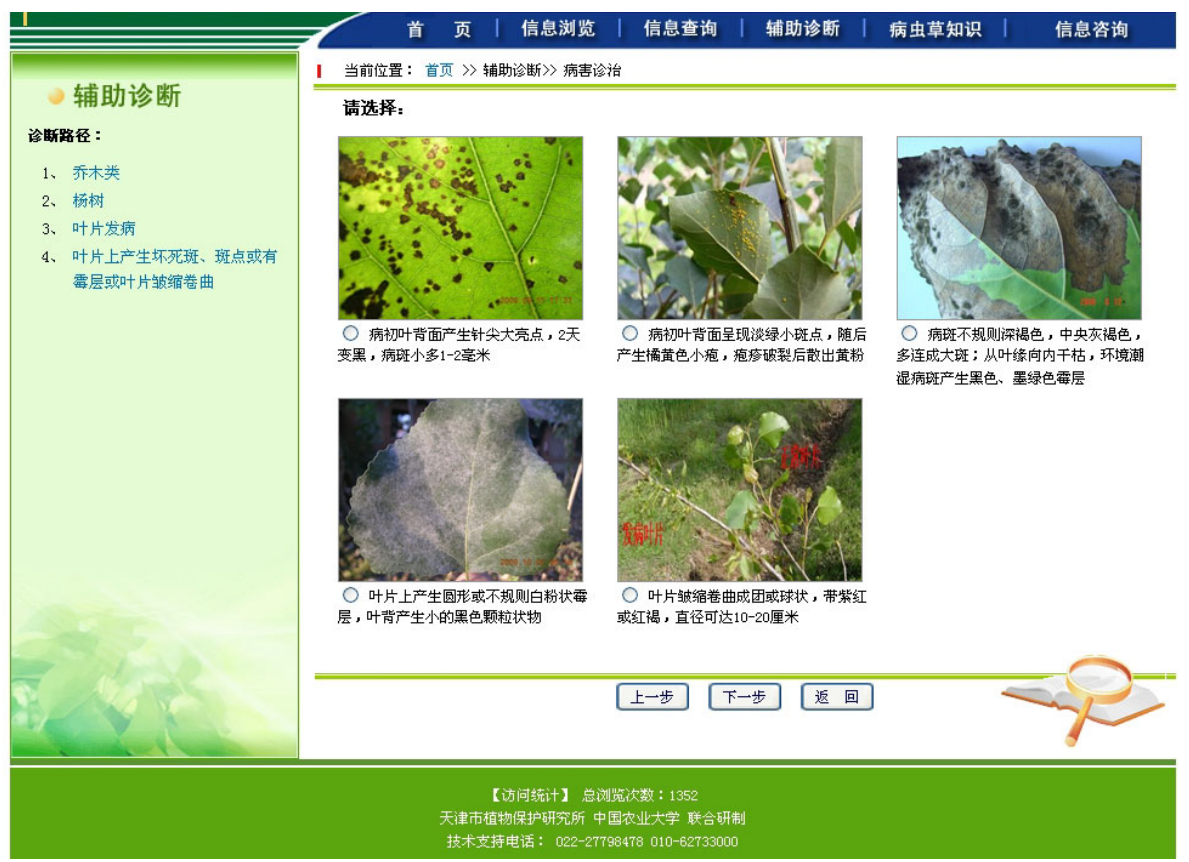

Fig. 2. The diagnosis page of TPPADS 
levels. The knowledge is distributed among many nodes [50]. Compared with dichotomous structure, TPPADS based on multi-branch structure or is another form of hierarchical structure has more advantages for accurate and rapid diagnosis (Fig. 1).

\subsection{Users Interface}

User interface is the direct media between users and computers. To best meet the different users' need, designers should insist on friendly principle. In another word, they should consider all users' knowledge level and ensure the interface complete, compact and easy (Fig.2). Meanwhile, data maintaining is also very easy and simple as same as the Microsoft Windows Explorer.

\section{Discussion}

Although ESs may respond faster and be more available than a human expert, are steady, unemotional, and give complete response at all times, they also do have the following disadvantages [51]:

- Some applications are difficult to use by another person who has not generated the knowledge-base.

- Some systems are very slow when compared to the human expert.

- The knowledge systems' ability tends to end abruptly.

- Sometimes, it is difficult to extract knowledge from an expert and to put it into a format that the ES can deal with and the size of the ES domain must be limited.

- The inability of ESs to exhibit common sense limits the effectiveness of present ES applications.

For expert systems, effective organization of expert knowledge has a great influence on the functions of the expert system. If it use rule-based structure, then adjusting of knowledge base becomes very difficult and the system's adaptive capacity be reduced greatly. TPPADS adopts the multi-branch structure design, which is more suitable for various needs and the flexible adjusting to changing demands. Thereby, it may save the cost of software development and reduce maintenance difficulty.

Further work includes that increasing of pest species involved, expanding the scope of application. Secondly, we should train technicians and farmers for using of the system. However, conceptually expert systems should not be considered absolutely valid or absolutely invalid, as the overall system evaluation is a continuous process and an ongoing endeavor helping to ensure maximum usage of the developed expert system [22]. So we must publicize the system as possible as more people can know and use it. The system included about more than 300 species of green plant pests. Diagnosis knowledge was obtained from Tianjin Institute of Plant Protection. TPPADS can be used as a diagnosis tool and information database both for plant protection professionals and farmers. We believe its application prospect should be well.

\section{Acknowledgements}

The authors would like to thank all technicians of Tianjin Institute of Plant Protection to give help to this study. We also thank other members of Plant Quarantine Lab, China 
Agricultural University. This study is supported by Cooperation Project of Agricultural Science and Technology of Tianjin (No. 0804100).

\section{References}

1. Weeks, P.J.D., Gauld, I.D., Gaston, K.J.: Automating the identification of insects: a new solution to an old problem. J. Bulletin of Entomological Research 87, 203-211 (1997)

2. Liao, S.H.: Expert system methodologies and applications-a decade review from 1995 to 2004. J. Expert Systems with Applications 28, 93-103 (2005)

3. Helvacioglu, S., Insel, M.: Expert system applications in marine technologies. J. Ocean Engineering 35, 1067-1074 (2008)

4. Blancard, D., Bonnet, A., Coleno, A.: TOM, un système expert en maladies des tomates. J. P.H.M. \& Revue Horticole1 261, 7-14 (1985)

5. Coulson, R.N., Saunders, M.C.: Computer-assisted decision-making as applied to entomology. J. Annual Review of Entomology 32, 415-437 (1987)

6. Jones, P.: Agricultural applications of expert systems concepts. J. Agricultural Systems 31, 3-18 (1989)

7. Travis, J.W., Latin, R.X.: Development, implementation, and adoption of expert systems in plantpathology. J. Annual Review Phytopathology 29, 343-360 (1991)

8. Goodenough, J.L., McKinion, J.M.: Basics of Insects Modelling. ASAE monograph, St. Joseph (1992)

9. Edwards Jones, G.: Knowledge-based systems for pest management: an application-based review. J. Pesticide Sciences 36, 143-153 (1992)

10. Carrascal, M.J., Pau, L.F.: A survey of expert systems in agriculture and food processing. J. AI Applications 6, 27-49 (1992)

11. Edwards Jones, G.: Knowledge-based systems for crop protection: theory and practice. J. Crop Protection 12, 565-575 (1993)

12. Ramon, M.C.U., Roland, F.: An expert advisory system for wheat disease management. J. Plant disease 78, 209-215 (1994)

13. Yialouris, C.P., Sideridis, A.B.: An expert system for tomato diseases. J. Computers and Electronics in Agriculture 14, 61-76 (1996)

14. Gonzalez Andújar, J.L.: Cereal aphids expert system (CAES): identification and decision making. J. Computers and Electronics in Agriculture 8, 293-300 (1993)

15. Gallagher, S.: Proceedings of the Inaugural Meeting of the BioNET International Group for Computer Aided Taxonomy (BIGCAT). TECSEC Press, The University of Wales (1997)

16. Kramers, M.A., Conijn, C.G.M., Bastiaansen, C.: EXSYS, an Expert System for Diagnosing Flower bulb Diseases, Pests and Non-parasitic Disorders. J. Agricultural System 58, 57-85 (1998)

17. Ellison, P., Ash, G., McDonald, C.: An expert system for the management of botrytris cinerea in Australian vineyards. J. Development, Agricultural Systems 56, 185-207 (1998)

18. Leslie Shipp, J., Clarke, N.D.: Decision tools for integrated pest management. In: Albajes, R., Lodovica Gullino, M., Van Lenteren, J.C., Elad, Y. (eds.) Integrated Pest and Disease Management in Greenhouse Crops, pp. 168-182. Kluwer Academic Publishers, Netherlands (1999)

19. Clarke, N.D., Leslie Shipp, J., Papadopoulos, A.P.: Development of the Harrow Greenhouse Manager: a decision-support system for greenhouse cucumber and tomato. Computers and Electronics in Agriculture, 24, 195-204 (1999) 
20. El-Azhary, E., Hassan, H.A., Rafea, A.: Pest control expert system for tomato (PCEST). J. Knowledge and Information Systems 2, 242-257 (2000)

21. Mahaman, B.D., Harizanis, P., Filis, I.: A diagnostic expert system for honeybee pests. J. Computers and Electronics in Agriculture 36, 17-31 (2002)

22. Mahaman, B.D., Passam, H.C., Sideridis, A.B.: DIARES-IPM: a diagnostic advisory rule-based expert system for integrated pest management in Solanaceous crop systems. J. Agricultural Systems 76, 1119-1135 (2003)

23. Gonzalez Andújar, J.L., Fernandez-Quintanilla, C., Izquierdo, J.: SIMCE: An expert system for seedling weed identification in cereals. J. Computers and Electronics in Agriculture 54, 115-123 (2006)

24. Prasad, R., Kumar Rajeev, R., Sinha, A.K.: AMRAPALIKA: An expert system for the diagnosis of pests, diseases, and disorders in Indian mango. J. Knowledge-Based Systems 19, 9-21 (2006)

25. Mansingh, G., Reichgelt, H., Osei Bryson, K.: CPEST: An expert system for the management of pests and diseases in the Jamaican coffee industry. J. Expert Systems with Applications 32, 184-192 (2007)

26. López-Morales, V., López-Ortega, O., Ramos-Fernández, J.: JAPIEST: An integral intelligent system for the diagnosis and control of tomatoes diseases and pests in hydroponic greenhouses. J. Expert Systems with Applications 35, 1506-1512 (2008)

27. Li, D., Fu, Z., Duan, Y.: Fish-Expert: a web-based expert system for fish disease diagnosis. J. Expert Systems with Applications 23, 311-320 (2002)

28. Fu, Z., Xu, F., Zhou, Y.: Pig-vet: a web-based expert system for pig disease diagnosis. J. Expert Systems with Applications 29, 93-103 (2005)

29. Xiao, J., Wang, H., Gao, L.: Design and Implementation of Expert System for Cow Disease Diagnose Based on. NET Framework. J. Application Research of Computers 12, 247-248 (2006) (in Chinese)

30. Liu, S., Xu, L., Shen, Y.: Design and implementation of expert system for prawn disease diagnose and prevention based on.NET platform. J. Computer Engineering and Design 13, 3444-3447 (2008) (in Chinese)

31. Kaloudis, S., Anastopoulos, D., Yialouris, C.P.: Insect identification expert system for forest protection. J. Expert Systems with Applications 28, 445-452 (2005)

32. Kaminaris, S.D., Tsoutsos, T.D., Agoris, D.: Assessing renewables-to-electricity systems: a fuzzy expert system model. J. Energy Policy 34, 1357-1366 (2006)

33. Alexandre Matelli, J., Bazzo, E., Carlos da Silva, J.: An expert system prototype for designing natural gas cogeneration plants. J. Expert Systems with Applications 36, 8375-8384 (2009)

34. Yialouris, C.P., Passam, H.C., Sideridis, A.B.: VEGES-a multilingual expert system for the diagnosis of pests, diseases and nutritional disorders of six greenhouse vegetables. $\mathrm{J}$. Computers and Electronics in Agriculture 19, 55-67 (1997)

35. Gao, L., Shen, Z., Liu, Z.: Design and development of Taxokeys, a dichotomous-reasoning-based multimedia expert system assisting insect identification and taxonomic study. J. Acta Entomologica Sinica 46, 644-648 (2003) (in Chinese)

36. Li, Z., Zhang, B., Shen, Z.: The development of Quarantine Pests Information and Identification System in China. J. Plant Quarantine 17, 273-276 (2003) (in Chinese)

37. Gonzalez Andújar, J.L.: Expert system for pests, diseases and weeds identification in olive crops. J. Expert Systems with Applications 36, 3278-3283 (2009)

38. Shao, G., Li, Z., Wang, W.: Study on vegetable pests remote diagnosis expert system (VPRDES). J. Plant Protection 1, 51-54 (2006) (in Chinese) 
39. Liu, G., Yang, X., Ge, Y.: An Artificial Neural Network-based Expert System for Fruit Tree Disease and Insect Pest Diagnosis. J. Networking, Sensing and Control, 1076-1079 (2006)

40. Peng, Y., Wang, Y., Tang, J.: A Study on Rice Pest Insect and Disease Diagnosis Expert System Based on B/S Mode. J. Acta Agriculturae Universitatis Jiangxiensis 6, 1157-1160 (2008) (in Chinese)

41. Han, H., Rajotte, E.G., Li, Z.: Qpais: A Web-Based Expert System for Assistedidentification of Quarantine Stored Insect Pests. In: Computer and Computing Technologies in Agriculture II, vol. I, pp. 701-714. Springer, Boston (2009)

42. Yu, S., Zhu, W.: Research on Mobile Expert System of Tomato Pest Diagnose Based on Microsoft.Net and Web Service. J. Journal of Agricultural Mechanization Research 1, 206-210 (2006) (in Chinese)

43. Wang, A., Miao, T., Cao, J.: Study of Web - Based Expert System for Control of Diseases and Insects in Forest. J. Computer Technology and Development 4, 228-231,235 (2008)

44. Xiao, L., Wang, Z., Peng, X.: Remote Diagnosis and Control Expert System for Citrus Agricultural Diseases and Insect Pests Based on BP Neural Network and WebGIS. In: Second International Conference on Intelligent Computation Technology and Automation, pp. 88-93 (2009)

45. Su, K., Liu, T., Hwang, S.: A developed model of expert system interface (DMESI). J. Expert Systems with Applications 20, 337-346 (2001)

46. Morpurgo, R., Mussi, S.: I-DSS: an Intelligent Diagnostic Support System. J. Expert Systems 18, 43-58 (2001)

47. Wada, T., Motoda, H., Washio, T.: Knowledge acquisition from both human expert and data. In: Cheung, D., Williams, G.J., Li, Q. (eds.) PAKDD 2001. LNCS (LNAI), vol. 2035, pp. 550-561. Springer, Heidelberg (2001)

48. Plant, R.E., Stone, N.D.: Knowledge-based Systems in Agriculture. McGraw-Hill, New York (1991)

49. Chandrasekaran, B.: Generic tasks in knowledge-based reasoning: high-level building blocks for expert system design. J. IEEE Expert 1, 23-30 (1986)

50. Schulthess, U., Schroeder, K., Kamel, A.: NEPER-weed: a picture-based expert system for weed identification. Agron. J. 88, 423-427 (1996)

51. Helvacioglu, S.: Utilization of expert systems in container ship design: accommodation layout design expert system (ALDES). Ph.D. Thesis, Department of Naval Architecture,Istanbul Technical University, Istanbul (2001) 